\title{
Applying a Grounded Theory approach in theory development on IS Investment Strategy for a Developing Country
}

\author{
Sam Lubbe (PhD) \\ Jan Meyer (PhD) \\ University of Zululand, North West University (Mafikeng campus) \\ Email: lubbes@unizulu.ac.za/Jan.meyer@nwu.ac.za
}

Doi:10.5901/mjss.2014.v5n20p2997

\begin{abstract}
The study determined that there was no theory available for managers on how to invest resources in IS/IT. The authors collected data and developed empirical generalisations that were tested and presented in the form of an IS/IT Investment Theory to a focus group, whose comments were utilized to further refine the theory from which we derived managerial guidelines. Some of the organisations that helped to develop the theory confirmed that they would be prepared to apply these guidelines.
\end{abstract}

Keywords: Grounded Theory, investment strategy, theory, developing country.

\section{Introduction}

The problem the authors identified was that there were no theoretically sound empirical guidelines available for practitioners on how to design a strategy to invest resources in IS and IT. This meant that data had to be collected and analysed to help design such a dependable strategy. Search engines and Meta search engines like Google, Yahoo, AltaVista and databases such as EBSCO and Science Direct were used using keywords such as IT investment in developing countries, IT in developing countries, etc. to prove the lack of theory in South Africa. The objective of this paper was to describe how case study evidence can be analysed and a theory for IS Investment developed to be able to list general principles relating to the assessment of the effectiveness of IT investment in SA. In addition, this paper discusses how correspondence analysis was used to validate findings of content analysis. The paper firstly discuss content analysis, look at the development of a theory, the use of correspondence analysis and finally list some guidelines that can be used.

\section{Results of the Content Analysis}

Content analysis is a process of investigating the frequency and intensity at which concepts are used in sources that deal with the themes under investigation. It is by nature a subjective process that utilizes content categories set up by the researcher (Kerlinger, 1969). The establishment of the manifest content categories is one of the main areas of possible subjective bias. The initial categories used in this research were issues of discussion raised by respondents a number of times during the research interviews, and as such were the ones chosen. Although bias will never be absent it is believed by the authors that there was little bias in the concepts. According to Berelson (1952), content analysis may be used with different units of analysis including words, themes, characters, items, and space time measurements. In this case the unit used was themes. It is regarded as one of the difficult units as a theme can be raised or eluded to in several different ways. The result of the content analysis was divided into 2 main sets of issues, IT Investment Drivers and IT Benefits. A list of the themes raised by informants and their frequency were developed. The nature of drivers is different as some drivers originate from the top (e.g. organisational strategy).

In the transcripts of the case study interviews there were 47 references to the importance of organisational strategy during the assessment of the effectiveness of IT investment in South Africa, etc. In the transcripts of the interviews there were also 49 references to the importance of productivity of as one of the benefits during the assessment of the effectiveness of IT investments in South Africa, etc. There were other issues discussed during the interviews, but these were not repeated by informants and are therefore not included in the list. 
It was felt reasonable that a theme must be important to the informants if it was to be incorporated into the theory this researched developed. A definition of the importance of a theme to the informants was established pragmatically by asserting that if a theme was mentioned 10 times or more it would be included. As only seven major IT investment themes and seven major IT benefit themes were identified during the content analysis by the author it was deemed enough and allowed all the results of the research to be included.

\subsection{The theory}

The primary purpose of conducting the case study research was to collect evidence with which to build a theory about how firms conduct the assessment of the effectiveness of IT investment. Thus, the case study work was exploratory leading to a theory that could be tested using a focus group approach. There are a number of different concepts of theory (Bailey, 1987). For the purposes of this research a theory may be defined as the explanation of a particular phenomenon, or a mechanism which will allow the prediction of how certain matters will interact. To be useful in the social sciences a theory must be sensible, logical, useful and testable. The test requirements relate to Popper's (1975) suggestion that a theory must be falsifiable. A theory consists of concepts which are related in statements known as propositions. A set of propositions may be combined to form a theory (Nachmias \& Nachmias, 1989). It is therefore the purpose of this part of the article:

- to establish the themes that are important to use during the assessment of the effectiveness of IT investment

- to state these themes in the form of propositions

- to combine these propositions into a theory.

These issues relate directly to the research questions which could be summarised as follows: How do SA organisations handle effective IT investments.

\subsection{Theory formulation}

The purpose of developing the theory is to explain how management assess the effectiveness of IT investments. If a satisfactory explanation can be developed, it could provide a basis for evaluation of IT investment management and allow understanding as to the success in a firm. From the results of the content analysis of drivers for IT investment, it can be deduced that organisational strategy and management decision factors are important drivers for the placement of an IT investment. From the results of the content analysis of drivers for IT benefits, it can also be deduced that productivity and new opportunities are important benefits organisations expect to receive from an IT investment. In order to assist with the interpretation of the results of the content analysis diagrammatic conceptual frameworks (Miles \& Hubermann, 1984) were developed which indicate how these themes are linked. These are shown in Figures 1, 2 and 3.

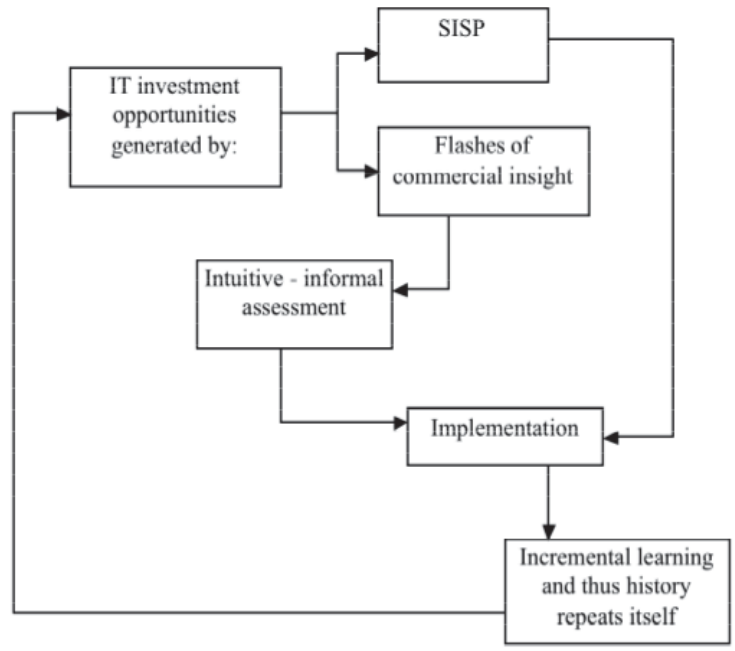

Figure 1: A traditional view of IT investment processes in SA organisations 
Figure 1 address traditional IT investment issues as they are presently used by the organisations studied. Some IT investments are decided upon during the Strategic Information Systems Planning process (SISP) but most of the time as a result of gut-feeling processes ("flashes of commercial insights"). The process is reiterative because only partial (incremental) insights are gained each time that the SISP is implemented. It can be noted that more than $70 \%$ of the organisations are not following any formal processes but rather look at opportunities or market orientation. According to the informants of the organisations these investments are therefore assessed during an informal process. The approach to the assessment of the effectiveness of IT investment planning, described in Figure 1, exhibited no specific characteristics, approaches and techniques.

Figure 2 displays a 'new' approach to the assessment of the effectiveness of IT investments. It exhibits the specification of IT investment targets and techniques that could be used during the IT investment process. One of the differences could be that a learning process is applied to each IT investment. Although there are differences in the practical application of the assessment of the effectiveness of IT investments, Figure 2 contains all the drivers for IT investments identified by the informants of the case studies. The logical process of Figure 2 is thus different from Figure 1. Figure 2 contains two processes, an IT investment process and an actual IT usage process. The process starts with a specification of IT investment targets. These targets could be achieved because of setting one or a combination of the reasons named by the respondents. These IT investment targets have to be decided upon by the superiors because of one or a combination of the reasons identified by them.

The next process during the IT investment process is the development of action programmes to achieve the IT investment targets. Once these action programmes have been developed a commitment to achieve the target is made between the superior and the subordinate. This could be done by reviewing action programmes and to agree on a certain level of benefits to be achieved. They will also agree on the eventual evaluation approach of the IT investment, ensuring that the IT investment is needed by the organisation.

The IT investment process involves finalising the expected standard of performance in terms of the previously agreed upon action programme before using the IT. The user should record actual benefits as the IT is being used, compare the actual benefit with the expected standard on a daily basis and discrepancies should be noted. On a threemonthly or six-monthly basis a major review of IT investment targets is undertaken, at which stage new targets are set. IT investment targets (Figure 2) will keep on changing because IT goal-posts keep on moving. IT investment objectives may not be reached as a result of these changes. The IT investment action plans should thus include strategies to

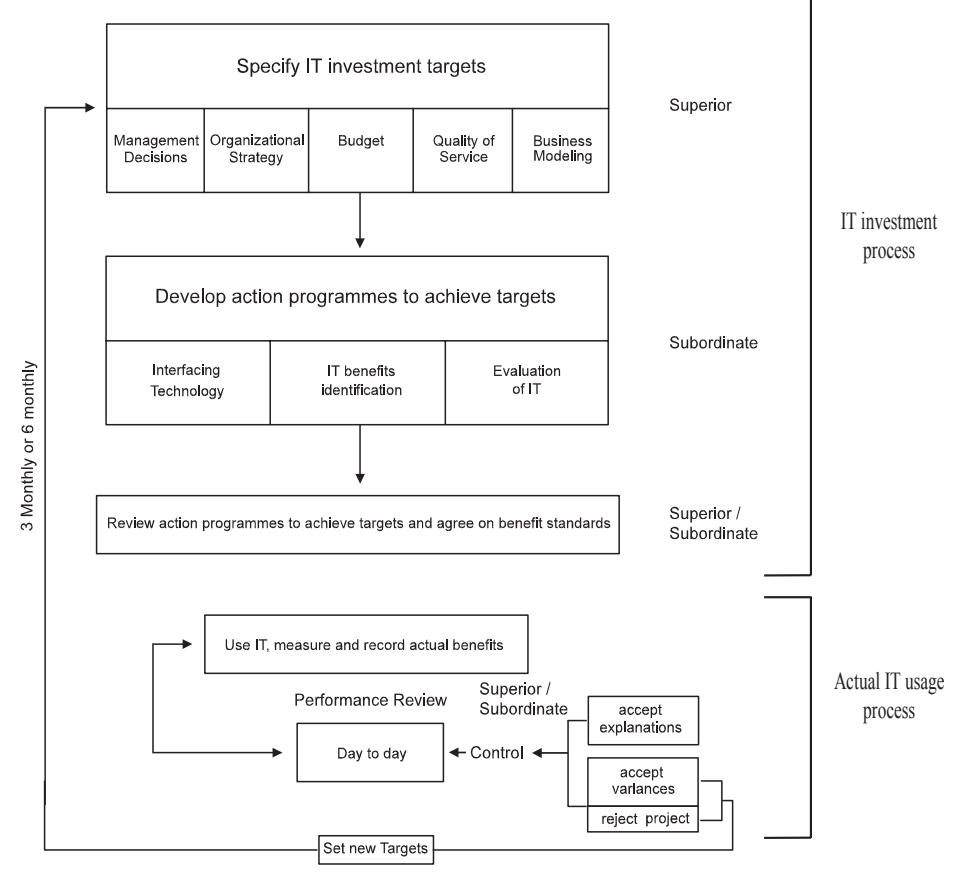

Figure 2: The proposed IT investment process and usage model 
i. Accept explanations for the differences (variances) between actual IT benefits and the benefit standard agreed upon.

ii. To accept variances in the light of changed circumstances but new targets will have to be reviewed and new benefits standards have to be set.

iii. Lastly, it could be a drastic decision whereby the superior decides to reject the IT investment totally, set new targets and specifies an IT investment action plan, starting the process all over.

The identification of IT benefits as set out on the next page (Figure 3) is a strategy suited to IT investment environments keeping risk (uncertainty) in mind. The process of IT benefit specifications, as summarised, seems to be appropriate. During the measurement processes, satisfactory performance is equated with the ability of managers to generate action plans aimed at improving the effectiveness of the IT investments and not by their ability to achieve a benefit that can change over time.

Figure 3 demonstrates the process of IT benefits management. Action programmes could be developed to achieve the benefit by managers who would review the forecasts programmes and agree on levels for the IT benefits to be reached. As IT is used, action programmes need to be improved and the benefits adjusted. The action would require involvement by managers before, during and after the IT investment process. If this process, as illustrated in Figure 2, is compared with the process of IT benefit realisation, it becomes clear that the IT investment process is a process aimed at improving the effectiveness of IT investments. IT realisation planning is the ideal approach during the IT investments and SISP that could help to improve IT investment.
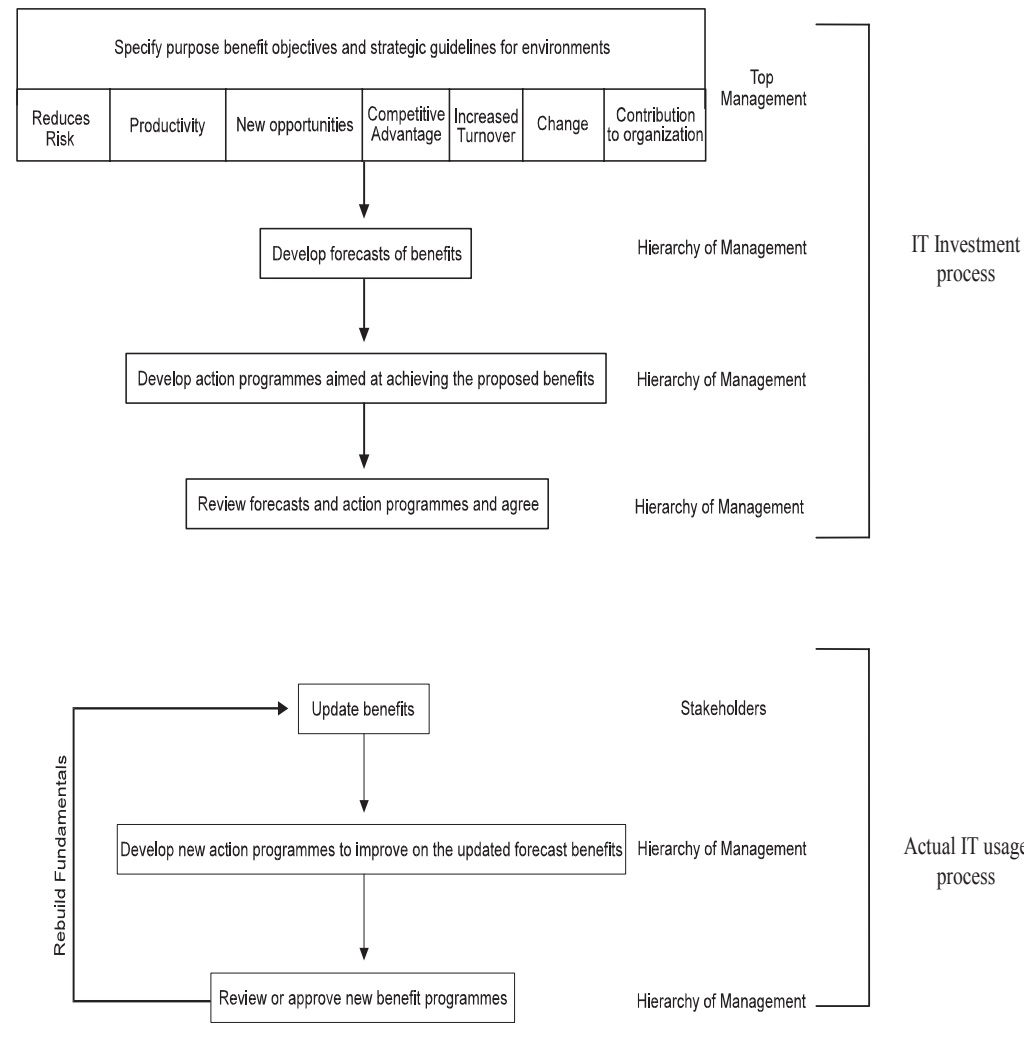

Actual IT usage process

Figure 3: A perspective on IT benefits - IT investment process and the IT usage process.

The management of IT investments would require the following information:

i. Internally generated information dealing with IT benefits identified by informants.

ii. Internally generated external information that has been formally gathered, processed and stored, dealing with 
the assessment of the effectiveness of IT investments that is critical to successful management of IT investments.

iii. A variety of specialised information dealing with specific decision situations that defied any attempt at prior definition (intangible benefits).

\title{
2.3 Empirical Generalisations
}

Using the content analysis as well as the evidence suggested by the various informants the following generalisations has been synthesised:

i. IT investments occur as a result of targets identified by top management because of one or more drivers classified.

ii. The organisation's response to the opportunity for the assessment of the effectiveness of IT investments is influenced by the themes affecting the IT investment process. Both tangible and intangible benefits are included.

iii. The decision to invest resources into IT is taken with the help of action plans (a strategy) aimed at achieving the IT investment targets.

iv. Attention is given to specification of benefit objectives (productivity, profitability, etc.), realisation of IT benefits and to communication with staff members of the organisation (see Figure 3 ).

These propositions, unlike hypotheses that strictly have to be stated in a testable form, which allows the relationship between two or more variables to be examined, and do not have this format requirement. An empirical generalisation is a proposition which is derived as a result of an exercise in deduction whereby propositions are constructed after observing themes and relationships in an empirical situation..

\subsection{The combined theory}

The four empirical generalisations may be combined into a theory which offers an explanation as to how the assessment of the effectiveness of IT investment are formulated and implemented:

\begin{abstract}
IT investments occur as a result of targets identified by top management because of drivers classified in Figure 2. These IT investment targets are developed into action plans in conjunction with subordinates and these are regularly reviewed by these two groups. The organisation's response to the opportunity for the assessment of the effectiveness of IT investment is influenced by the themes affecting the IT investment process shown in Figure 3.

The empirical generalisations above comply with the requirements of sensible, logical as well as testable or falsifiable. Correspondence analysis was used to help corroborate how the findings of the content analysis interpret the theory. As correspondence analysis provides a perceptual map of the data, it provided a deeper insight into the multivariate nature of the data.
\end{abstract}

\subsection{Correspondence analysis}

The two-dimensional matrices used were demonstrated in Table 1. The primary result of the correspondence analysis is a map identifying the row and column attributes as points in a space of two or more dimensions. Table 1 shows the result of the content analysis detailed by participating industry.

Table 1: Summary results - IT investment drivers

\begin{tabular}{|c|l|c|c|c|c|c|c|c|c|c|c|c|c|c|}
\hline & & & $\mathbf{1}$ & $\mathbf{2}$ & $\mathbf{3}$ & $\mathbf{4}$ & $\mathbf{5}$ & $\mathbf{6}$ & $\mathbf{7}$ & $\mathbf{8}$ & $\mathbf{9}$ & $\mathbf{1 0}$ & $\mathbf{1 1}$ & Total \\
\hline 1 & Organisational strategy & $\mathrm{OS}$ & 9 & 1 & 3 & 5 & 8 & 5 & 2 & 3 & 5 & 2 & 4 & 47 \\
\hline 2 & Management decisions & $\mathrm{MD}$ & 8 & 2 & 6 & 4 & 5 & 5 & 2 & 6 & 4 & 2 & 2 & 46 \\
\hline 3 & Interfacing & $\mathrm{FB}$ & 1 & 1 & 5 & 2 & 14 & 0 & 2 & 0 & 0 & 0 & 3 & 28 \\
\hline 4 & Quality of Service & $\mathrm{QS}$ & 2 & 1 & 3 & 2 & 4 & 10 & 0 & 2 & 0 & 0 & 3 & 27 \\
\hline 5 & Evaluation of IT & $\mathrm{IF}$ & 1 & 0 & 3 & 4 & 3 & 5 & 2 & 1 & 3 & 0 & 2 & 24 \\
\hline 6 & Business Modelling & $\mathrm{MS}$ & 2 & 1 & 4 & 1 & 4 & 0 & 0 & 5 & 0 & 0 & 3 & 20 \\
\hline 7 & Budget & $\mathrm{EI}$ & 0 & 0 & 4 & 4 & 4 & 5 & 0 & 0 & 0 & 0 & 2 & 19 \\
\hline & Total & & $\mathbf{2 3}$ & $\mathbf{6}$ & $\mathbf{2 8}$ & $\mathbf{2 2}$ & $\mathbf{4 2}$ & $\mathbf{3 0}$ & $\mathbf{8}$ & $\mathbf{1 7}$ & $\mathbf{1 2}$ & $\mathbf{4}$ & $\mathbf{1 9}$ & $\mathbf{2 1 1}$ \\
\hline
\end{tabular}


All sections were extracted using xISTAT. The INERTIAS (Eigen values) and PERCENTAGES OF INERTIAS are both a table and a histogram. This report determines the number of dimensions required to explain the original data set. It may be stated (IT investment drivers) that one dimension will explain $50 \%$ of the total data variability and that two-dimensions will explain $79 \%$ of the variability. By using two-dimensions more than three quarters may be explained.

Figure 4 is an example of a perceptual map which shows the relative position of the different themes and the different participating informants. As previously mentioned OS, MD and FB represent respectively organisational strategy, management decisions and interfacing etc. and I1, etc. represent the different participating industries.

The perceptual map is the key product of correspondence analysis which shows how the row and column variables may be grouped. Figure 4 also shows the centre of gravity and the chi-squared distances for the IT investment drivers.

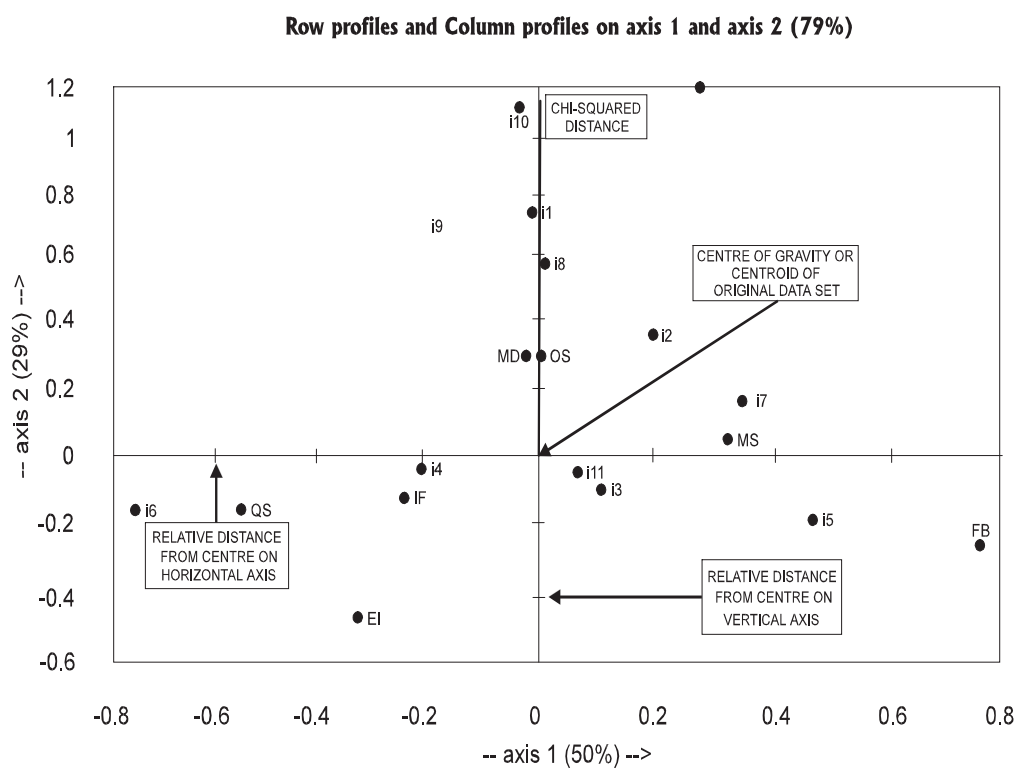

Figure 4: The perceptual map with the intercept, axes and distances explained

From Figure 4 it is possible to see that some of these themes and participating industries may be conveniently grouped together (e.g. the three themes IF, QS and El are to the left of the intersection of the axes, and the themes MS and FB are to the right of the axes). The themes of quality of service, evaluation of IT and budgeting may all be described as being of an evaluative orientation, and it is not surprising that these themes lie in proximity on the horizontal axis. The industries that fall close to this area on the graph could be described as having an evaluative approach to IT investment. Business modelling and interfacing may also be described as part of the business processes and these themes lie in proximity, on the horizontal scale, to one another. The fact that these themes are not spread on the vertical axis support the grouping on the horizontal axis. The industries that fall close to this area on the graph could be described as having a business process focus to IT investments. These two variables represent a bi-polar dimension with evaluative orientation on one end of the scale and business processes on the other. Figure 4 shows the grouping on the horizontal line.

With regards to the vertical axis, the themes of MD and OS are grouped together. They constitute a closely knitted pair that on the horizontal axis is closer together but away from the origin. The themes of management decisions and organisational strategy may be described as strategy or policy issues and these lie in proximity to one another. The industries that fall close to this area on the graph could be described as having a strategic orientation. Figure 5 shows an example of the grouping of these themes on the vertical axis (dotted lines). At the other end of the vertical axis there are the themes of QS, IF and FB. The projection of these themes on the vertical axis may be seen to be close and therefore there seems to be an association between them on this dimension. 


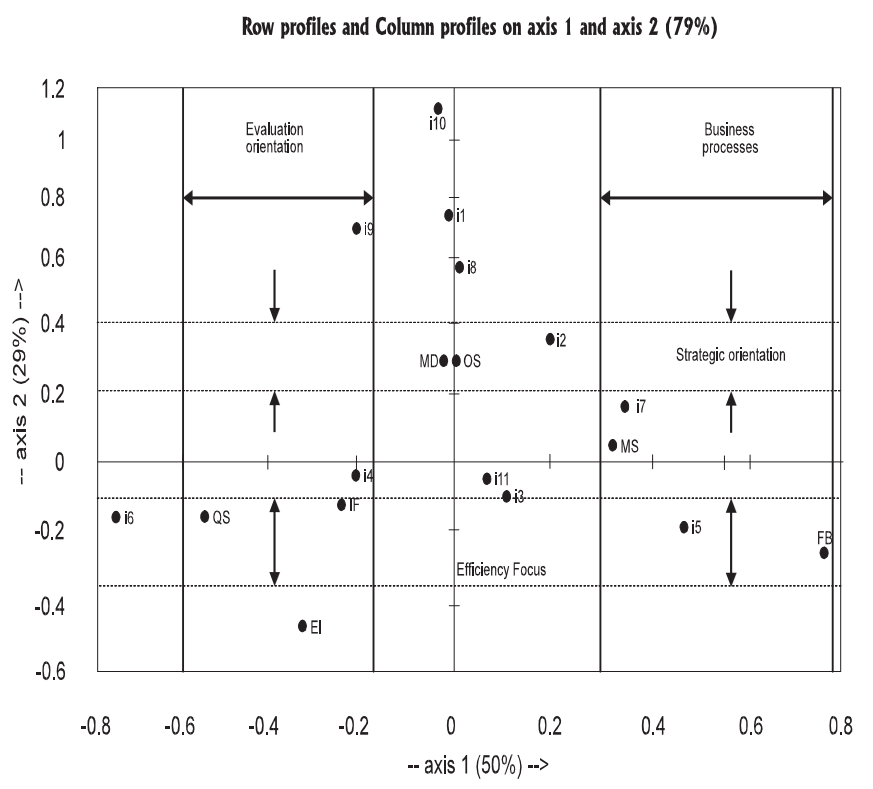

Figure 5: The perceptual map with the horizontal and vertical axis defined

All the themes that are interfacing, evaluation of IT and quality of service are efficiency issues and industries in this area could be described as efficient. Themes which are all grouped together on the perceptual map show there is a relationship between these variables. The perceptual map does not indicate the type of relationship. The specification of the nature of the relationship depends on the environment being described by the correspondence analysis. Therefore from the correspondence analysis described the authors can state that the organisations that participated perceive the issues of quality of service, evaluation of IT and interfacing as associated.

The issues of management decisions and organisational strategy all had similar values on the horizontal and vertical axis and they are a group of issues. The quality rating for business modelling is low and therefore is not necessarily close to the horizontal axis, as it is on a third dimension that cannot be represented two-dimensionally. This suggests that interfacing is treated differently. This perceptual map demonstrates that interfacing is an efficiency focus issue, whereas business modelling appears to be relevant to strategic issues. This does not correspond to the idea that some organisations will use the process of modelling their business processes as a motivation for IT investments and could reflect in their strategy.

\section{The Use of Correspondence Analysis to Analyse IT Investment Benefits}

The next part of content analysis was detailed by participating organisations allocated into industries. The reports determine the number of dimensions required to explain the original data set. One dimension in this study will explain $58 \%$ of the total data variability and two dimensions will explain $82 \%$ of the variability. Therefore by using two dimensions more than $3 / 4$ of the variability may be explained.

With regards the vertical axis, the themes of $\mathrm{CO}, \mathrm{CA}$ and IC constitute a cluster, which on the horizontal axis CA and IC are close together about the origin, and on the vertical axis are closer together but away from the origin. The three themes of competitive advantage, increased turnover and contribution to the organisation may be described as profitability issues and that these themes lie in proximity to one another. Enterprises that fall close to this area could be described as having a profit focus. At the other end of the vertical axis are the themes RR, PB and CB. The projection of these themes onto the vertical axis may seem to be close and there seems to be an association between them on this dimension. All three of reducing of risk, productivity and change in the business processes are productivity issues and industries in this area could be described as productivity orientated.

All these issues seem to be in close proximity and seem to be associated. Themes which are grouped together on 
the perceptual map are associated. Therefore, informants perceive the issues of reduced risk, new opportunities and productivity as associated. The issues of increased turnover, competitive advantage and contribution to the organisation have similar values on the vertical axis and they are a group of issues. Similar arguments could be used of contribution to the organisation and change in business processes. The quality rating for new opportunities is low and therefore it is not necessarily close to the horizontal axis, as it is on two dimensions. The two variables of reduced risk and productivity have different vertical axis scores and shows that reduced risk and productivity are treated differently. This perceptual map shows both reduced risk and productivity as part of the productivity and performance issues. This corresponds with the idea that organisations will want to improve their productivity by increasing their performance and this will be reflected in their IS policy.

\section{Presentation of the Theoretical Conjecture to a Focus Group and Practitioners and Refinement of Conclusions}

The aim of this is therefore to describe feed back obtained from the focus group and the practitioners (IT people and consultants) and their reaction to the theoretical conjecture and the models suggested by the research. The reactions of these expert informants are also interpreted and the conclusions of the research refined were a cross validation procedure.

\subsection{The reasons for using a focus group}

In order to verify whether the theory derived from the evidence collected during the case study phase of the research commands support from practitioners in business. It was therefore decided to discuss the theoretical conjecture and the models with expert informants. The focus group provided an opportunity to falsify the empirical generalisation which the authors generated. They subsequently met with ideas arising from the research. These discussions were started off by the researcher but he allowed the people to freely discuss the ideas generated by the research because he did not want to influence the outcome of the focus groups.

The focus groups consisted of practitioners, academics and consultants. The three models, shown previously in Figures 1, 2 and 3, presented the IT investment process (historically and proposed) and benefits identification and development process were discussed. The empirical generalisations relate to the following IT investment issues which are:

i. Drivers for IT investment (targets).

ii. Response to the opportunity created.

iii. Achieving and evaluating IT investment targets.

iv. Benefits to be realised with the assistance of the IT investment.

The focus group agreed to critically review the document and the models that were created. The review was in the form of a discussion. As a result of the feedback obtained from the focus group minor changes were made to some of the suggestions.

\subsection{Results of the focus group discussion}

Empirical generalisation 1:

IT investments occur as a result of targets identified by top management because of one or more drivers classified identified earlier.

The focus group agreed that the principle should apply as is it was stated. Although the author explained the term budget to the budget group they suggested that the term budget constraints rather be used.

Empirical generalisation 2:

The organisation's response to the opportunity for the assessment of the effectiveness of IT investments is influenced by the themes affecting the IT investment process. The precise theme directly dictates the evaluation process which will be used. Tangible benefits will be measured financially and intangible benefits will be measured qualitatively.

The focus group agreed that more people should be involved with IT investment decision and that the term stakeholders would be a better description to describe involvement of the people.

Empirical generalisation 3:

The decision to invest resources into IT is taken with the help of action plans (a strategy) aimed at achieving the IT 
investment targets like efficiency (quality of service), improving business processes (modelling), etc. with attention to detail concerning the ability of managers to review and update these action programmes in conjunction with subordinates (see Figure 2 and Figure 6).

The focus group agreed there should be a chance in the terminology; benefit should be replaced by the word outcome. Benefit identification was changed to outcome identification and review action programmes to achieve targets and agree on benefit standards were changed to read ... agree on outcome standards because some organisations do not use benefit identification.

Empirical generalisation 4:

Attention is given to specification of benefit objectives (productivity, profitability, etc.), realisation of IT benefits and to communication with staff members at all levels of the hierarchy of the organisation (see Figure 3 and Figure 7).

The word benefit was replaced by the word outcome in Figure 7 (compare Figure 3 and Figure 7). They also agreed that the benefits identified could be replaced by other organisations by themes that they want to use. The focus group was satisfied with the findings in general. However, they agreed that the first model (Figure 7) needs some adapting. A revision period of $3-6$ monthly might not always fit in with the current revision plans of the organisation and they therefore agreed that it should be re-adjusted to read appropriate time interval.

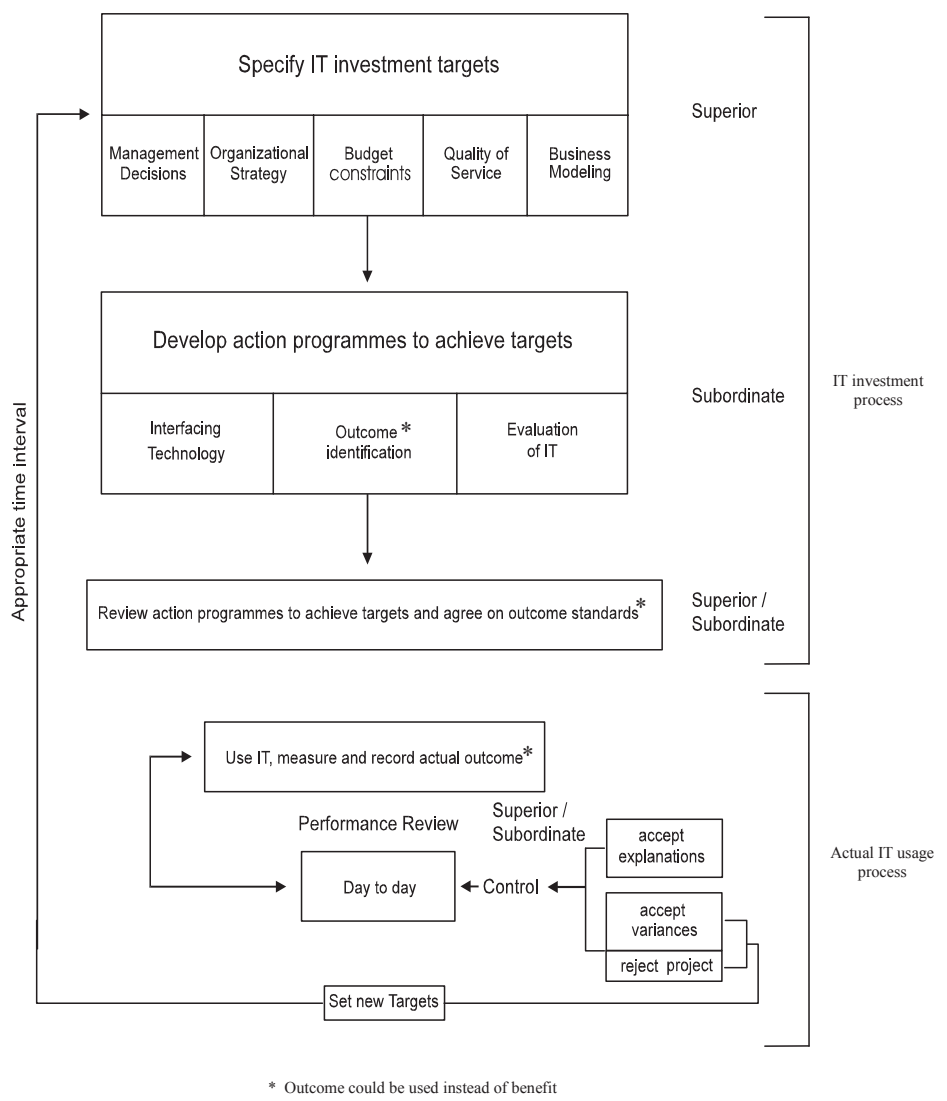

Figure 6: The IT investment process and usage model with suggested changes made

In general it could be noted from the discussion by the focus group that complex systems (organisations) show certain common behaviours and should be studied as a unit. It would useful to holistically study the interaction between IT and the components within the system. 


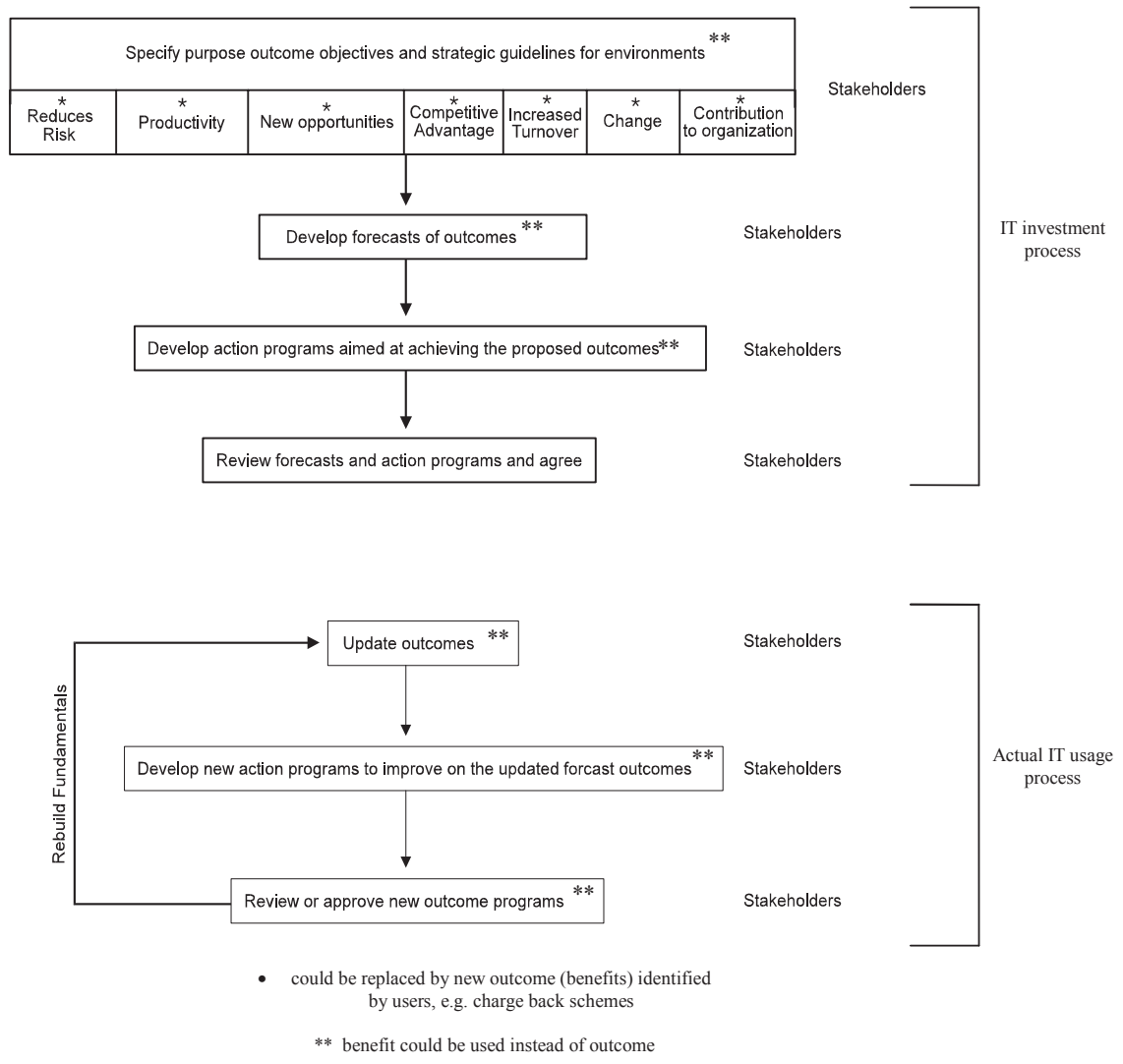

Figure 7: Adopted perspective on IT outcome (benefits) - IT investment and actual IT usage

No changes were required by the focus group of the theory created by the study. The theory accepted was thus:

IT investments occur as a result of targets identified by top management because of one or more drivers classified. These targets are developed into action plans in conjunction with subordinates and these are regularly reviewed. The organisation's response to the opportunity for the assessment of the effectiveness of IT investment is influenced by the themes affecting the IT investment process as shown in Figure 2. The decision to invest resources into IT is taken with the help of action plans (a strategy) aimed at achieving the IT investment targets like efficiency (quality of service), improving business processes (modelling), etc. with attention to detail concerning the ability of management to update the action programmes.

Attention is given to the specification of outcome (benefit) objectives (productivity, profitability, etc.), realisation of IT outcome (benefits) and to communication with staff members at all levels of the hierarchy of the organisation. It is important to include all outcomes (benefits), both tangible and intangible. Evaluation is conducted regularly for control purposes and the result of the evaluation may be one of the three outcome described in Figure 2. When the evaluation dictates a change to the system, outcome (benefit) profiles and programmes are updated and rebuilt as per Figure 6.

\section{Practical Management Guidelines}

The research needed to create a series of management guidelines that will assist organisations in applying formal procedures when making any IT investments. These guidelines have been developed from the theory and the models as well as from the results of all the different evidence gathering activities undertaken by the author during the research. The 10 principles so developed reflect all the key elements of the theory further developed into the form of management guidelines for IT investment.

In order for IT investment are to be formulated, implemented and evaluated in an effective format, the practitioner should 
i. Clarify top management targets. IT investments occur as the result of targets identified by top management.

ii. Get to know the drivers for IT investment well.

iii. Develop IT investment targets that are clear and understandable to all parties in the organisation.

iv. Outcome (benefit) objectives should be spelled out clearly because they would affect the action plans that would ensure the success of the IT investment. It applies to both tangible and intangible outcome (benefits).

v. Ensure that all persons measuring and noting outcome (benefits) have a known and reliable performance index or measure with which to evaluate each outcome (benefit) type.

vi. Determine the attitude of top management.

vii. The organisation must ensure that staff involvement receives the required attention.

viii. Develop adequate support facilities which can handle a wide range of problems.

ix. Look for IT investment targets across a wide range of issues, especially in areas that relate directly to the IT strategy and organisational strategy. IT outcome (benefits) should be high on the lists of targets searched for. Regular evaluation needs to be conducted to ensure outcome (benefit) realisation.

x. Adequately staff the IT investment process and implementation with suitably trained and experienced personnel.

It is clear that such a practical management guideline requires considerable time and resources. Also top managers need to be committed to ensure that all concerned promptly comply with these guidelines and that certain people do not get side-tracked by departmental issues. In applying the guidelines suggested, many organisations would have to face management change of a cultural change exercise.

\subsection{Results of the presentation to the practitioners}

Senior practitioners from four of the original case study organisations were approached to discuss the theory, models and the practical management guidelines. The correspondence analysis figures (Figures 8 and 5) were also shown to these senior practitioners in order to validate the results of the content analysis for IT investment drivers and IT outcome (benefits) identified.

\subsubsection{Organisation no 1}

The presentation was to one of the organisations in the transport industry that participated in the original case study. The informants indicated that they strongly agree with the findings and recommendations of the research and indicated that they would like to apply some (if not all). They investigated all the aspects mentioned and noted that the study was what they needed to help them manage their IT and they regarded the study as very useful.

The study addressed their questions regarding IT investment. They requested permission to use the models that were adapted and noted that they would give further feedback to the author in due course. It could be possible to use the organisation as a model and apply all the aspects and conduct a separate case study on the application of the findings of the study. The informant invited the author for another session as they are in the process of studying the models in more details and would like advice on how to apply some of the processes identified. They point out that it would need a lot of training and education in because not all top managers were convinced of the importance of IT investment. They were happy with their position on the correspondence analysis grid.

\subsubsection{Organisation no 2}

The second respondent stated that they were satisfied with the findings. They were in the process of changing the way they address the IT investment process in the organisation. The principles presented to them were issues that they felt should be addressed but were not always the case. They believe however that it would not too difficult to achieve the suggested type of management thinking in their organisation.

The respondents felt that the little progress they were making, the case study done and aspects mentioned in the study would help them to improve on the way they handle all IT investments. He felt that the principles discussed during the presentation were very useful and that some of these aspects have already been incorporated into the organisation's own IT investment procedures. 


\subsubsection{Organisation no 3}

The third practitioner was also positive about the findings of the research and the fact that they could make use of it. They noted that their position on the correspondence analysis figure was the correct one for their organisation and industry. They also noted that they were employing most of the principles listed in the models. IT investment, it seems have been successful in their organisation, despite the recognition that they need to improve their procedures. The study, according to them, was a firm attempt to do it and that they would like time to study these processes and apply those that they were not doing. They claimed that their staff would welcome their organisation formally adopting an IT investment process as described in the research study findings.

\subsubsection{Organisation no 4}

The fourth practitioner was also complimentary about the findings. In fact he indicated that the study brought out aspects that should be paid more attention in his organisation. He also indicated that the place of his organisation and industry were also plotted 'correctly' and that it was a promising study in that it highlighted aspects that bigger organisations tend to accept as normal. He also mentioned that the human aspect should be highlighted. He also mentioned that the practical guidelines should be a useful framework for his organisation.

\section{Concluding Remarks}

\subsection{How South African organisations identify IT investments?}

Organisations sometimes identified IT investments as flashes of commercial insight and sometimes they identified an IT investment target because of some drivers like a management decision, budgetary constraints, and quality of service or business modelling. These drivers were identified, an investment decision made and action programmes set to reach the IT investment target. It can be concluded that South African organisations have to be more systematic about the identification of investments. They need to identify reasons (drivers) for the IT investment and then develop action programmes to achieve these targets.

\subsection{How organisations measure the impact of IT investments on organisational performance?}

Most of the organisations conducted an informal assessment of the impact of IT investment. They regarded the impact as part of the outcome (benefits) they gained from doing the IT investment. Some organisations for instance noted the increase of productivity of their employees. It could be part of the drive to allow their staff to spend more productive time in front of the computer. Another factor that was measured by the organisations was increased turnover measured in the form of a percentage.

It can be recommended that specific targets for measurement should be developed, performance reviews completed and reports given to management. Action should then be taken in the following format, e.g. the variance should be accepted and the IT investment should continue, or the variances should be accepted but new targets should be set for the IT investment or lastly drastic action could be taken whereby the organisation rejects the IT investment totally and start a new IT investment.

\subsection{Formulation of IT investments in South African organizations}

It is clear from the research that setting action plans for IT investment are not an easy matter to formulate and to implement. Opportunities for proper IT investment strategies are not always that obvious, what appears to be a possible action plan for IT investment sometimes amount to nothing, or is too complicated or too expensive to implement. How to accommodate IT investment action plans into the organisation's current IT strategy is not always easy. For this reason it is important to have a set of explicit guidelines.

Key among these guidelines is the idea of drivers that could act as a reason for IT investment in a variety of ways. It is crucial for any organisation to be aware of these drivers and how they change. Environmental scanning could support the drivers and subsequent action plans. 


\subsection{Which criteria are used to evaluate the IT investment projects?}

Organisations in South Africa claim to use a variety of criteria to evaluate the IT projects. Most of the organisations do not use a specific evaluation method but a combination of visual processes to evaluate the IT investment. Some of these criteria involve outcome (benefits) that organisations identifies like new opportunities, competitive advantage that the organisation can achieve by placing the IT investment, new business opportunities, etc.

Action programmes should be developed to evaluate the IT investment and achieve the targets spelled out by the stakeholders. It can be suggested that all interested parties, i.e. stakeholders, should be involved in the process. It starts with the specification of outcome (benefit) objectives through meetings, etc. Stakeholder involvements may of course, also have begun through the action plan formulation for the IT investment process proposed by management. Where possible an attitude of communication partnership should be put between all the interested parties within the stakeholder group. However, the senior person in the group should be the representative of the group and the owner of the IT investment. The key ingredients to make it work are to develop specifications for outcome (benefit) forecasts and training. These are on-going commitments across the life cycle of the IT investment and they must be properly planned for and accounted for into the IT investment.

In addition, successful realisation of IT outcome (benefits) relies on careful planning and reviewing, and organisations should be spending more time and money on the planning of the realisation of IT outcome (benefits) process. IT investment and outcome (benefit) realisation cannot succeed without appropriate staffing and it requires a lot of detailed planning and precise execution. It is a costly process which organisations should only undertake after appropriate consideration. The above research questions were also answered by the models shown in Figure 2 (6) and Figure $3(7)$.

\section{Final Conclusion: A General Issue}

Generally, some interest has been shown in the subject of IT investment and its evaluation. All the informants, consultants, academics, practitioners, etc. with whom the author had discussions throughout the research were very enthusiastic and helpful about the subject. Many of the informants were pleased to be involved in research on the subject.

The results of the focus group discussions and the presentations to the practitioners also supported the view that in South Africa a large number of organisations considered IT investment and outcome (benefits) identification to be an important issue. In fact the situation may be seen to constitute two groups, one which is very large and quite enthusiastic, and one which is small and not very keen. Therefore, it is clear that IT investment evaluation and IT outcome (benefits) identification is likely to remain an important subject for practitioners, consultants and academics for quite some time in the future. The research is, however, an original approach in South Africa to the assessment of the effectiveness of IT investment and that no other similar research, using such an approach, exists in South Africa. The research, however, did not address how to identify the different levels of IT investments or predict what outcome (benefits) could be derived form any IT investment. It is undoubtedly an area for future investigation.

It appears from the research that there is a trend towards combining the issues of formulation and implementation of IT investments and the identification of IT outcome (benefits) together, as effective IT investments will benefit from a seamless approach from start to finish. It is reflected in a generally higher level of awareness of organisations concerning the importance of IT investment.

\section{References}

Bailey K.D. 1987: Methods of Social Research. The Free Press, New York Berelson, B. 1952: Content Analysis in Communication Research. New York: Free Press. Kerlinger F.N. 1969: Foundations of Behavioural Research. Holt Rhinehart and Winston, London Miles M.B \& Hubermann A.M. 1984: Qualitative data analysis: A sourcebook of new methods. Sage Publications, London Nachmias C. \& Nachmias D. 1989: Research methods in the Social Sciences. Edward Arnold, London Popper K. 1972: cited in Harre R. The Philosophies of Science: an introductory survey. Oxford University Press 